\title{
IDEAL AND NONIDEAL MORAL THEORY FOR DISASTER BIOETHICS
}

\author{
DÓNAL O’MATHÚNA
}

\begin{abstract}
Moral theory has generally focused on resolving ethical dilemmas by identifying ethically sound options. Whether the focus is on consequences, duties, principles or virtues, ethical cases are often approached in ways that assume morally sound solutions can be found and followed. Such 'ideal morality' assumes that moral goodness is always possible, leaving people confident they have done the right thing. Such an approach becomes inadequate in disaster settings where any good solution is often difficult to see. This paper examines recent work on nonideal moral theory as a useful model for disaster bioethics. This approach views moral dilemmas as situations where no choice is ideal and every option involves some element of unavoidable wrongdoing. Rather than straining for ideal answers, this approach acknowledges that sometimes the lesser of two evils is the best that can be done. Such situations inevitably lead to feelings of regret or guilt, commonly encountered in discussions of disaster bioethics. This paper explores the practical implications of nonideal approaches for disaster responders working in tragic situations.
\end{abstract}

Key words: nonideal theory; disaster; triage; emotions; personalism.

\section{Introduction}

The ethical dilemmas encountered in disasters are often complex and convoluted. Many lead to what has been called the "humanitarian conundrum" (Lepora \& Goodin, 2013, p. 3). To provide help in situations of natural devastation or ruthless conflict, it can seem impossible to avoid doing some bad in order to bring about any good. To care for some people, it looks like others must be ignored or left to die. To get aid to needy people, some engagement with the bad guys seems necessary. How much wrongdoing can be ignored, condoned or even carried out, in the name of doing good? These questions are faced by individuals, for example turning a blind eye in order to help others, and by organisations, for example providing aid knowing that some of it will line the pockets of those in power or allow a conflict to continue. In other situations, should a policy be supported knowing it will permit some discrimination to continue even while outlawing the worst rights violations that currently occur without censure?

Such questions raise challenging issues for those hurled into the midst of disasters. Responders come from diverse backgrounds, including healthcare professionals who volunteer to help injured and traumatised survivors. The outpouring of well-intentioned help 
is often tainted by criticisms about lack of preparation, coordination, and appropriate skills (Krin et al., 2010). Sometimes responders do act unethically, such as 'disaster tourists'medical responders more interested in excitement and fame than patients' needs (Van Hoving, Wallis, Docrat, \& De Vries, 2010). Most healthcare responders go to serve victims, yet can return from disasters experiencing what has been called "vicarious traumatisation," "compassion fatigue," or "burnout," although definitions for these terms vary (Alexander \& Klein, 2009, p. 88). While this paper will focus on healthcare professionals, many similar issues are faced by researchers and other aid workers who face ethical decisions within their areas of response (O’Mathúna, 2015).

The negative experiences of disaster responders relate to the devastation they see, the human pain and suffering they witness, physical fatigue, frustration with difficult working conditions, and ethical dilemmas. Some of the same ethical challenges arise in non-disaster settings, but they are intensified in disasters by the degree of scarcity, the extensive needs, differences in cultural, social and professional norms, and poorly defined roles. At the same time, many responders report positive impacts of their work during disasters, especially the development of resilience. Frontline healthcare workers have reported that their work during an outbreak had positive impacts through opportunities to reassess their life values and priorities, and deepen their relationships with co-workers and others (Alexander \& Klein, 2009). Similarly, many who stayed to fight Ebola within their local communities, or who left home to serve in Ebola regions, reported some positive experiences (von Drehle, 2014).

Responders often face ethical dilemmas, but these have received relatively little attention until recently (Sheather \& Shah, 2011). Triage decisions are the most obvious: choices must be made to treat some people and not others. These decisions should be based on objective, medical criteria, but in the field the guidelines can be far from clear-cut, leading to conflict over how and whether to follow them (Merin, Ash, Levy, Schwaber, \& Kreiss, 2010). Some conclude that utilitarianism is the ideal ethical theory to apply in public health and disaster settings (Wagner \& Dahnke, 2015). This emphasises the principle of utility by which ethical problems are solved by calculating which action maximises the happiness, pleasure and well-being of the greatest number of people (Slim, 2015). For example, if one oxygen tank remains, using it for several people who need it short-term has better consequences than using it for one person who needs it long-term (Fink, 2010). Yet utilitarian thinking is fraught with difficulties, including the inherent uncertainty in predicting outcomes, the risk that individuals and minorities will disproportionately suffer for the sake of the majority, the undervaluing of individual rights, and the endorsement of overly paternalistic approaches in the name of the common good.

Others favour Kantian or deontological approaches where the focus is on duties. Such theories emphasise the importance of respecting all humans by treating all persons as ends in themselves and not as mere means to others' ends. Ethical actions are those based on duties to other which in recent times are seen to arise from human rights. Disaster response in general can be seen as ethical because people's rights to life and health place a duty on others to help in time of need, especially the extreme need that disasters bring. However, ethical dilemmas arise when different duties cannot be fulfilled at the same time. If a military medical unit has accepted civilian casualties, what should they do when severely injured soldiers arrive? Healthcare professionals will see they have a duty to their existing patients 
(the civilians), but as members of the military they have a duty to their comrades. They may be ordered to transfer the civilians to local hospitals, even knowing these do not have the resources to keep the patients alive (Ritchie, 2011). Their mandate may be clear, but their consciences may not. Such decisions may be justifiable on the basis of duty, but their impact on responders, and trust with the local community, may be detrimental.

A Canadian research team has interviewed many humanitarian healthcare workers about the ethical dilemmas they face (Schwartz, Hunt, Redwood-Campbell, \& de Laat, 2014). They identified four general themes underlying most ethical difficulties in humanitarian work, including with disasters.

- Resource scarcity leads to ethical questions about who should receive the available resources and in what order. For example, should the most seriously injured be treated first, or those most likely to recover quickly with the fewest resources? If vaccines are in short supply, should responders or children or the elderly receive them first?

- Working in places where pre-existing social injustices arise from historical inequalities, political or commercial institutions, or cultural differences. What if local authorities insist that their families are helped first, or refuse to allow aid to be given to a minority group? Should discrimination be tolerated for the greater good?

- Frustration with aid agency policies or agendas, especially when these conflict with professional ethical duties. What does a doctor do with a patient with a chronic disease when her agency insists on treating only those acutely injured by a disaster? Doing what seems right for the patient may cause problems for the agency, or risk losing the support of funders.

- Addressing healthcare professional hierarchies, poorly defined roles, and differing scopes of practice or standards of care. Should a nurse carry out a medical procedure outside his scope of practice because he offers the patient her only chance of recovery? He risks harming the patient in the hope of helping her.

Many of the above situations involve both ethical and practical problems. If responders with the correct expertise are sent, others will not have to practice outside their professional credentials. More resources could resolve many of the ethical dilemmas. Yet disasters inherently involve limited resources and lead to questions of justice and fairness in their distribution. While disaster training is increasingly recognised as important for healthcare professionals, Hurricane Katrina showed that this needs to include preparation for the resulting ethical dilemmas (Fink, 2013). Yet a systematic review of qualitative research involving nurses and disasters found that nurses were clinically and emotionally unprepared for disasters with "a failure to directly address the issue of ethical considerations in planning, preparedness, and response to public health emergencies and disasters by nurses" (Johnstone $\&$ Turale, 2014, p. 73). Healthcare professionals who are unprepared to deal with such ethical dilemmas are at risk of emotional, psychological and moral distress (Wagner \& Dahnke, 2015). They also risk making bad decisions.

\section{Nonideal theory}

Disasters are also challenging ethicists and philosophers to consider how moral theory can best contribute to ethical decision-making in disasters. Debate is sometimes framed as a 
disconnect between 'ideal theory' and 'nonideal theory.' Ideal theory typically abstracts from the specifics of a situation or issue to identify general principles that allow the right answer to be determined. Western ethics training usually focuses on resolving ethical dilemmas in rational ways by identifying ethically sound options and justifications for choosing one over the other. Such 'ideal morality' assumes that moral goodness is always possible. Ethics is seen as a way to help people act ethically, leaving them confident that they have done the right thing. Moral dilemmas, in this approach, either do not really exist or show that further analysis is needed to identify ideal ethical solutions (Tessman, 2010).

When such an approach is used in disasters, its inadequacy becomes apparent. Humanitarian ethical dilemmas often involve choosing between options where none are good. Rather than finding ideal (or even good) solutions, the least worst option often seems the best. An ideal approach to ethics leads to frustration and guilt, as Schwartz and colleagues found (2014). Some then question whether ethical theory has any value in disasters. Maybe the situations are too complex or abnormal to allow any normative claims. Yet with every disaster, reports arise that things were not done ethically. Allegations are made that people were treated badly, that supplies were not distributed fairly, that responders did not do what they should have done. Disaster responses are expected to be conducted ethically and therefore ways of thinking through the ethical dilemmas are needed.

Nonideal moral theory provides a useful model for disaster ethics. This paper does not propose a new moral theory for disaster ethics, but a way of applying moral theory within a nonideal framework. In this approach, "moral dilemmas should be understood as situations of unavoidable moral wrongdoing or failure" (Tessman, 2010, p. 798). Ideal approaches focus on ideal situations and abstract principles, but actual disasters may differ greatly to what has been conceptualised. Nonideal approaches start by describing the real world, including its wrongs and injustices. It admits that, "Not all wrongs can be rectified, not all losses can be compensated, not everything can be repaired or replaced, and-especially given the limits of psychological resilience-not everyone can recover (Tessman, 2010, p. 801). True moral dilemmas exist where all options carry a bad side. As a result, some degree of moral failure must be acknowledged and with that, some sense of emotional regret or remorse.

The following case, recounted by a female doctor from a real situation, exemplifies some of the features of the ethical challenges that can arise in disaster settings.

At the end of a medical information session in a very poor war-torn country, a young soldier came up to me. He asked whether he should use condoms when engaging in rape.

I answered 'yes'. I was in little doubt that he should use condoms at all times, and in even less doubt of his duty not to rape. But was that the right answer to that specific question? That seemed debatable.

Assuming it is anyway better for a woman to be raped without getting an infection or an unwanted pregnancy, rather than being raped with those added harms, I should answer 'yes'. But would answering 'yes' make me complicit in rape? Should I instead have lied about the efficacy of condoms, hoping for a deterrent effect? Would not answering at all have been any better for myself, or for him, or for any subsequent person he raped? (Lepora \& Goodin, 2013, p. 1) 


\section{The role of emotions}

Every answer to this soldier's question will leave moral, intellectual and emotional questions unanswered. All the options written by the doctor have good and bad components. No answer is ideal. Yet an ideal approach to moral theory suggests that ethical principles or duties or virtues can be weighed and considered until the ethical answer is identified: the right way forward. A nonideal approach accepts that no ideal solution may exist. With triage, even if the choice of one patient over another can be justified ethically, those deciding will likely be left with mixed feelings. Making some decisions for the greater good, even though some bad is also done, "may be ethically the best choice, all things considered. Still, contributing to 'bads' in this way rightly grounds the agent's feeling of having done something wrong" (Lepora \& Goodin, 2013, p. 4). An ideal approach to ethics claims this should not be so; a nonideal approach sees this as an unavoidable part of making tough decisions in a messy world, such as in disasters.

Ideal theories do not necessarily reject the emotional components of ethical decisionmaking. But they often focus exclusively on the rational dimensions leading to certain emotional reactions being views as illogical. The role of emotion in morality has thus sometimes been ignored, leading to a neglect of the appropriateness in moral conflicts of feelings like regret, remorse, or shame. Bernard Williams (1965) noted this trend and objected that if two or more moral obligations truly conflict, someone can be acting for the best and also have regrets. Ethical theory and training should help to prepare people to face such ethical dilemmas, and assist responders in the field as they wrestle with such decisions and their consequences, both practical and emotional. This requires addressing the emotional dimensions of ethics, including guilt, forgiveness, grief and anger.

Ideal theory coveys the sense that an ideal answer can be found in which the agent is completely without fault. No bad feelings should result, no sense of guilty, no moral hangover. This leads to the denial of true moral conflicts, exemplified by Immanuel Kant's claim that because duty and obligation "express the objective practical necessity of certain actions... It follows, therefore, that a conflict of duties and obligations is inconceivable" (DeCew, 1990, p. 29). If this is the case, a sense of regret or remorse when one has done one's very best is irrational. The rational person should not feel that way. But even if, on balance, the greater good resulted, this is "an incomplete way of assessing the moral state of affairs" (Lepora \& Goodin, 2013, p. 9). Williams more bluntly declared this approach "to be just false" (1965, p. 110).

Tragic cases, whether in literature, history or the news, support Williams and exemplify how the right moral decision may include doing something wrong. At the very least, one's intentions may have been mixed. Doctors may take care of patients because they truly believe it is their duty, has good consequences, and is right, yet at the same time begrudge some aspect of caring for certain patients. An ideal approach to one theory may emphasise that so long as we are fulfilling our duties, our intentions do not matter. Another ideal approach may claim that so long as the greater good is done for most people, we don't have to feel bad. Humanitarian workers return from the field after doing much good for many people, and yet also deeply regret not being able to help those they left behind. Ten people may be treated effectively and recover fully, but the face of one patient who was turned away and later died can haunt disaster responders. 
A nonideal approach seeks to account for these feelings, acknowledge those that are appropriate, and incorporate them into the overall ethical assessment. In many complex, tragic situations, including disasters, bad feelings are part of moral decision-making. When actions are causally connected to some wrong-doing, however compensated for by good deeds, some degree of moral responsibility remains. Feelings of regret and remorse indicate that this moral residue needs to be taken into account. Nonideal theory seeks to reflect the reality of what happens in situations where people do the best they can ethically and yet feel bad about their decisions. In a nonideal world, the ethical solution may be the least worst option, rather than an ideal solution.

Acknowledging that ethical decisions may include good and bad elements can also help to preserve trust in the midst of complex situations. Nonideal moral theory is not a form of relativism where the bad aspect becomes good because of the larger situation. When an ideal solution is sought, and regret viewed as illogical, the negative impact can be neglected or hidden. If wrong is done, even if unavoidable and ethically justified overall, it should be acknowledged as such. Holding out for ideal solutions can lead to a failure to acknowledge the wrong components, however impossible it may have been to avoid them. "But all too often, defenders of humanitarian action point lazily to the purity of motives underlying it, as if that in itself settles anything morally. Detractors point, almost as lazily, to the fact that some bad consequences can flow from humanitarian interventions, without reflecting on whether there are more good consequences than bad or on whether, however it actually turned out, the intervention might have been the right thing to do on the basis of what was and could have been known at the time" (Lepora \& Goodin, 2013, p. 11). Nonideal theory provides a way to honestly and openly acknowledge the good and the bad dimensions of decisions reached in ethical dilemmas in disasters.

\section{Individual goods and the common good}

Contemporary bioethics has come to emphasise the role of individuals in ethical decisionmaking. When faced with complex ethical issues in healthcare, various ethical principles have been identified which must then be prioritised. Arguably the most well-known method in the field is that of Beauchamp and Childress (2012). Their book, now in its seventh edition, identifies four ethical principles as central to bioethical decision-making, the first of which is respect for autonomy. This principle can conflict with others, but autonomy has come to be viewed as the key ethical principle in resolving ethical conflicts. Beauchamp and Childress declared that respect for autonomy is fundamental in bioethics, and a professional obligation not just a mere ideal. Within an ideal approach to ethics, one principle is necessary to provide a way to find clear-cut answers. However, the resulting priority given autonomy has been critiqued both on philosophical grounds (Greaney, O'Mathúna, \& Scott, 2012) and on empirical grounds (Christen, Ineichen, \& Tanner, 2014). While an ideal approach that claims to find clear solutions is attractive, in practice it generates further dilemmas, especially when conflicts arise between one person's autonomy and another's, and whether there are limits to one's autonomy.

In disasters, this ideal approach quickly runs into problems. Disaster responses sometimes include restricting people's freedoms for various reasons such as prioritising the 
common good over individuals' autonomy. Disaster ethical dilemmas are similar to those in public health ethics, which is characterised as being focused on questions of rationing, restrictions, and responsibilities (Petrini, 2010). In disasters, some injured people may be triaged to receive no treatment beyond comfort care, which can be problematic for healthcare practitioners familiar with well-resourced settings. Triage can run "counter to the moral intuition of most people and most nurses, as well as counter to the typical ethical principles that normally inform daily nursing practice. The nurse's instinct is to help and nurture the patient. To ignore this instinct causes great consternation with extreme and potentially longlasting moral distress" (Wagner \& Dahnke, 2015, p. 300). Many disaster responders, not just nurses, struggle with such ethical decisions.

Part of the problem is that one ideal theory or principle is sought to show the path to a clear resolution of the dilemma. Modern Western ethical thinking has been dominated by either the utilitarian "absolute single rule of utility" or by the deontological "series of absolute duties" (Slim, 2015, p. 127). Consequences and duties do matter in ethics, but so do a lot of other factors such as people's character (virtue), relationships and experience. An ideal approach tends to suggest that one factor will always solve the dilemma, while a nonideal approach allows for a complex balancing of competing principles and theories. It takes away the expectation that an ideal solution must be found, and thus validates the bad feelings that come with less than ideal solutions. Each ideal on its own can lead to extremes that create further dilemmas. But in a nonideal approach, all ethical factors are considered, while acknowledging that all may not be upheld ideally. This can lead to a framework for resolving ethical dilemmas by prioritising the relevant ethical principles through open, transparent discussions with all stakeholders. The solution may be nonideal, but the approach can be honest and open, accepting that no solution is without problems or limitations.

\section{Personalism}

One such approach to ethical dilemmas will be mentioned here, admitting that further work is necessary to develop its application to disaster bioethics. Such work is on-going. Personalism is an approach to ethics based on the premise that the public good is best promoted by care and respect for individual rights and well-being (Petrini \& Gianotti, 2008; Petrini, 2010). Personalism holds that all humans share a common nature or personhood which demands that all humans be treated with respect. At the same time, this approach admits that ideal answers to dilemmas may not always be found, and hence takes a nonideal approach. In this, five person-centred principles are considered and weighed as ethical dilemmas are reflected upon case-by-case, whether in disasters or any other situation.

- The principle of inviolability: all human life is inherently valuable and should be protected and respected. Actions should not diminish the dignity of individuals. This prohibits using any human as an instrument for the public good.

- The therapeutic principle: interventions on human life should always promote life. In clinical ethics, a part can be sacrificed for the good of the whole body (e.g. amputation of a mangled limb). In contrast, public health interventions should not deliberately cut short some human lives for the good of all. In extreme circumstances, some may be allowed to 
die who might elsewhere have been saved; but their dignity must still be upheld, such as with palliative care.

- The principle of subsidiarity: public health measures that preserve and promote individual choice are preferred over compulsory approaches. Education is preferable to coercion. Mandatory programs require a higher level of justification and evidentiary support.

- The principle of solidarity: individuals should take into account the needs of others and their communities as they make individual choices. A sense of togetherness, even in a global context, should lead to a prioritization of the needs of the most disadvantaged. Through promoting concern and care for the least well off, all will benefit.

- The principle of justice: resources should be fairly distributed and discriminatory actions and policies avoided.

Rather than focusing exclusively on consequences or duties or any other single principle, personalism seeks to express the core insights of several ethical theories in broadly accepted principles. When ethical dilemmas arise, rather than seeking one ideal solution, personalism accepts that ethical decision-making should involve balancing several principles that conflict. Other situations called symmetrical dilemmas (like triage), do not involve conflicting principles, but one ethical principle that cannot be upheld equally for all those involved. Wisdom and experience are needed in all these dilemmas, pointing to the importance of developing ethical virtues in decision-makers (Kalokairinou, 2016, this issue). Even then, especially in symmetrical dilemmas, a nonideal approach accepts the bad feelings as legitimate. To account for this, decisions should be reached after various perspectives are considered through open, transparent dialogue that respects all persons impacted. Approaches like personalism have only recently been applied to public health ethics, and are beginning to be explored in the context of disaster bioethics (Petrini \& Gainotti, 2008).

\section{Conclusion}

A nonideal approach will not easily solve the ethical dilemmas in disasters, but provides an approach that better recognises the limitations in these settings and likelihood that no decision will be ideal. Because of these factors, people will not feel completely good about any ethical decision. For example, in the case presented earlier about the soldier and condoms, no response will be fully satisfactory. The following is an example of how a nonideal approach could consider this case. This not presented as an ideal solution, but as one proposal that would require further discussion with those directly involved.

The principle of inviolability rules out accepting that the doctor say 'yes' and leave it at that. The soldier plans on violating other women, and thus more must be done. Some attempt to convince the soldier that rape diminishes the dignity of women is needed. The soldier has opened a door with his question, maybe revealing some pangs of conscience. This would also promote subsidiarity, and the hope that the soldier might decide against rape. The doctor should seize the opportunity to criticise rape, validate women's dignity, and promote the principles of solidarity and justice. Saying nothing about the wrongs of rape would violate all these principles. Similarly, saying 'no' or nothing at all would miss such potential opportunities.

At the same time, speaking up could put the doctor at risk of personal harm, or have implications for her clinic. There are likely to be negative consequences. An ideal approach 
looks for a solution with a clearly positive answer. Such may not exist. A nonideal approach allows for the fact that decisions are made looking forward with incomplete information and uncertainty. The doctor does not know how the soldier will react. Hindsight is a luxury for after the crisis. No matter what happens, the doctor may regret what she does or says. A nonideal approach accepts this as part of working in disasters and conflict settings. The doctor has been asked an impossible question. By seeking to persuade the soldier against rape, she is doing what she can to promote ethical principles. Even if he does not listen, or even feels emboldened by her answer, she is not responsible for his actions. The doctor may do all she can, and yet continue to feel bad about the situation. Such is the reality of true moral dilemmas, which nonideal theories acknowledge.

Accepting a nonideal approach to ethics does not mean giving up on ideals or accepting lower ethical standards. Striving after ideals is part of human flourishing. At the same time, there are circumstances where we must accept that all options are less than ideal. Some view this as accepting that life is so thoroughly confusing that it is absurd. "Striving in the face of the absurd permits one to maintain a claim on what one is unjustly denied (full personhood); the absurdity lies in the fact that the strivings will never attain their goal, but must be carried on nevertheless; to give up striving would be to announce one's acceptance of the injustice" (Tessman, 2009, p. 56). A vision of the ideal is good until it sets up expectations that success requires an ideal conclusion. The best that can be attained in disasters is often less than ideal. For that reason, a nonideal approach has much to offer disaster bioethics.

\section{Acknowledgments}

I am grateful for feedback on an early version of this paper provided by Vilius Dranseika, two reviewers of the paper, and participants at the workshop on moral theories and disasters at the University of Prešov, Slovakia (13-15 May 2015). Funding for this workshop and open-access publication was provided by COST Action IS1201 (http://DisasterBioethics.eu).

\section{References}

Alexander, D. A., \& Klein, S. (2009). First responders after disasters: A review of stress reactions, atrisk, vulnerability, and resilience factors. Prehospital and Disaster Medicine, 24(2), 87-94.

Beauchamp, T. L., \& Childress, J. F. (2012). Principles of biomedical ethics (7th ed.). Oxford: Oxford University Press.

Christen, M., Ineichen, C., \& Tanner, C. (2014). How "moral" are the principles of biomedical ethics? - A cross-domain evaluation of the common morality hypothesis. BMC Medical Ethics, 15(47). Retrieved from http://www.biomedcentral.com/1472-6939/15/47

DeCew, J. W. (1990). Moral conflicts and ethical relativism. Ethics, 101(1), 27-41.

Fink, S. (2010, February 23). Medical ethics in disasters. Doctors face ethical decisions in Haiti. Public Radio International. Retrieved from http://www.pri.org/stories/2010-02-23/doctors-face-ethicaldecisions-haiti

Fink, S. (2013). Five days at Memorial: Life and death in a storm-ravaged hospital. New York: Crown.

Greaney, A.-M., O’Mathúna, D. P., \& Scott, P. A. (2012). Autonomy and choice in healthcare: Selftesting devices as a case in point. Medicine, Health Care and Philosophy, 15(4), 383-395. 
Johnstone, M.-J., \& Turale, S. (2014). Nurses' experiences of ethical preparedness for public health emergencies and healthcare disasters: A systematic review of qualitative evidence. Nursing and Health Sciences, 16(1), 67-77.

Kalokairinou, E. M. (2016). Why helping the victims of disasters makes me a better person: Towards an anthropological theory of humanitarian action. Human Affairs, 26(1), 26-33.

Krin, C. S., Giannou, C., Seppelt, I. M., Walker, S., Mattox, K. L., Wigle, R. L., \& Crippen, D. (2010). So you want to help? BMJ, 340, 290-293.

Lepora, C., \& Goodin, R. E. (2013). On complicity and compromise. Oxford: Oxford University Press.

Merin, O., Ash, N., Levy, G., Schwaber, M. J., \& Kreiss, Y. (2010). The Israeli Field Hospital in Haiti - Ethical dilemmas in early disaster response. New England Journal of Medicine, 362(11), e38.

O’Mathúna, D. P. (2015). Research ethics in the context of humanitarian emergencies. Journal of Evidence-Based Medicine, 8(1), 31-35.

Petrini, C. (2010). Triage in public health emergencies: Ethical issues. Internal and Emergency Medicine, 5(2), 137-144.

Petrini, C., \& Gianotti, S. (2008). A personalist approach to public-health ethics. Bulletin of the World Health Organization, 86(8), 624-629.

Ritchie, J. (2011). Combat medicine: When every turn is toward death. Today's Christian Doctor, 42(3), 14-17.

Schwartz, L., Hunt, M., Redwood-Campbell, L. \& de Laat, S. (2014). Ethics and emergency disaster response normative approaches and training needs for humanitarian health care providers. In D. P. O'Mathúna, B. Gordijn, \& M. Clarke (Eds.), Disaster bioethics: Normative issues when nothing is normal (pp. 33-48). Dordrecht: Springer.

Sheather, J., \& Shah, T. (2011). Ethical dilemmas in medical humanitarian practice: Cases for reflection from Médecins Sans Fronti res. Journal of Medical Ethics, 37(3), 162-165.

Slim, H. (2015). Humanitarian ethics: A guide to the morality of aid in war and disaster. London: Hurst.

Tessman, L. (2010). Idealizing morality. Hypatia, 25(4), 797-824.

Tessman, L. (2009). Feminist eudaimonism: Eudaimonism as non-ideal theory. In L. Tessman (Ed.), Feminist ethics and social and political philosophy: Theorizing the non-ideal (pp. 47-58). Dordrecht: Springer.

Van Hoving, D. J., Wallis, L. A., Docrat, F., \& De Vries, S. (2010). Haiti disaster tourism-A medical shame. Prehospital \& Disaster Medicine, 25(3), 201-202.

von Drehle, D. (2014, December 22). The Ebola fighters. Time Magazine. Retrieved from http://time. com/time-person-of-the-year-ebola-fighters

Wagner, J. M., \& Dahnke, M. D. (2015). Nursing ethics and disaster triage: Applying utilitarian ethical theory. Journal of Emergency Nursing, 41(4), 300-306.

Williams, B. A. O. (1965). Ethical consistency. Proceedings of the Aristotelian Society, Supplementary Volumes, 39, 103- 124.

School of Nursing \& Human Sciences

Dublin City University

Dublin 9, Ireland

E-mail: donal.omathuna@dcu.ie 